\title{
Determinants of Ownership and Utilization of Insecticide-Treated Bed Nets for Malaria Control in the Kanifing Municipality, the Gambia
}

\author{
Alieu Jallow ${ }^{1}$, Ousman Bah ${ }^{1}$ and Ousman Bajinka ${ }^{2 *}$ \\ ${ }^{1}$ Department of Public and Environmental Health, Faculty of medicine and Allied Health Sciences, University of The Gambia (UTG), Gambia \\ ${ }^{2}$ University of The Gambia, School of Medicine and Allied Health Sciences, Gambia \\ *Corresponding Author: Ousman Bajinka, University of The Gambia, School of Medicine and Allied Health Sciences, Gambia.
}

Received: June 01, 2019; Published: July 17, 2019

DOI: 10.31080/ASMI.2019.02.0312

\begin{abstract}
Background: Malaria remains a major cause of mortality and morbidity in the world, and particularly in sub-Saharan Africa. Despite big increases in the supply of mosquito nets, especially of LLINs in Africa, the number available is still far below what is needed in almost all countries. Household surveys showed that the coverage of all interventions is lower than the $80 \%$ target set by the World Health Assembly. The aim of this research was to investigate magnitude and associated factors determining ownership and utilization of bed nets to control malaria in the kanifing Municipality.

Methods: A community based cross sectional study design using multi-stage sampling method. Both quantitative and qualitative approaches were instituted using interviewed structured questionnaires. Both univariate and bivariate analysis were used in analyzing the data. The binary logistic regression model with significance level set at $5 \%$ was used to determine predictors of bed net utilization. Data entry and analysis were conducted using SPSS version 24.

Results: The prevalence of current utilization of ITNs were 235 (61.5\%) while in terms of ownership, 298 (78.0\%) were found to owned/have mosquito nets in their households. The significant predictors of ITN utilization includes the size of the family in the household, 0.855 (95\% CI: 0.798 - 0.916); having mosquito nets in the households, 11.806 (95\% CI: 5.513 - 25.279); having nets in the sleeping spaces, 1.732 (95\% CI: $1.443-2.078)$ and reporting that bed net can reduce the incidence of malaria were $3.902(95 \%$ CI: 1.215 - 12.531).

Conclusion: Despite free distribution of LLINs during mass campaigns and routine government health facilities distribution, the ownership was moderately high and utilization remains low. Thus, there is a need to refocus on people's choice of bed nets including the textural properties in order to increase the utilization of ITN to effectively and efficiently control malaria in the municipality. Furthermore, the distribution centers and bed nets choices of individuals as in conical and soft texture should be increased during routine and mass LLIN campaigns.
\end{abstract}

Keywords: Malaria; Insecticide Treated Nets; Ownership and Utilization

\section{Abbreviations}

ACT: Artemisinin-based Combination Therapies; EAs: Enumerated Areas; GBOS: Gambia Bureau of Statistics; HMIS: Health Management Information System; IPTp: Intermittent Preventive Therapy; IRS: Indoor Residual Spray; ITNs: Insecticide Treated Nets; KM: Kanifing Municipality; LLINs: Long Lasting Insecticide Treated Nets;
MICS: Multiple Indicator Cluster Survey; NMCP: National Malaria Control Programme; RBM: Roll Back Malaria; RDT: Rapid Diagnostic Tests; SMC: Seasonal Malaria Chemotherapy; SPSS: Statistical Package for Social Sciences; UNICEF: United Nation International Children Fund; WHO: World Health Organization. 


\section{Introduction}

Malaria is an entirely preventable and treatable mosquito-borne illness. In 2015, 95 countries and territories had ongoing malaria transmission and an estimated 3.2 billion people - nearly half the world's population - were at risk of malaria. Malaria is a major public health problem in tropical and subtropical regions of the world [1].

During the last decade, malaria control and prevention efforts in the Gambia have been accelerated with increased availability of resources aimed at reducing the disease burden. As part of efforts to improve program performance, the Ministry of Health and Social Welfare in collaboration with Roll Back Malaria partners conducted a Malaria Program Review (MPR) between 2011 and 2012. The results of the MPR highlighted strengths, weaknesses, opportunities and threats as well as challenges to malaria prevention and control (MICS 2015).

Following the recommendations of the MPR, the 2008-2015 National Malaria Strategic Plans was revised and updated. Currently, the new strategic plan is aligned with Roll Back Malaria targets. The vision of 2014 -2020 malaria policy is "A Malaria-Free Gambia" and aims to achieve pre elimination slide positivity rate of $\leq 5 \%$ by 2020.The strategic plan places emphasis on universal coverage for key malaria interventions and seeks to consolidate the gains already achieved. Therefore, it will provide basis for a common ground for co-ordination, implementation and monitoring and evaluation of malaria control activities (MICS 2015).

In the Gambia, malaria continues to remain a leading cause of morbidity and mortality among children under the age of five years (GBoS), 2007). However, recent studies have indicated that malaria cases and admissions in government health facilities are on the decline. Findings between 2003 and 2007 from four health facilities with complete slide examination records show a decrease in the proportions of malaria-positive slides by $82 \%, 85 \%, 73 \%$, and $50 \%$ respectively. In two hospitals the proportions of deaths attributed to malaria fell by $100 \%$ and $90 \%$. Since 2004, mean haemoglobin concentrations for all-cause admissions increased by $12 \mathrm{~g} / \mathrm{L}$, and mean age of paediatric malaria admissions increased from 3 to 9. (Ceesay., et al. 2008). In spite of the decline recorded in cases reporting to health facilities, malaria remains a major killer disease especially among infants and children under five years of age.
A combination of tools and methods are now used to combat malaria in The Gambia and they include long-lasting Insecticidal Nets, (LLIN); Artemisinin-based Combination Therapy (ACT), supported by Indoor Residual Spraying of insecticide (IRS) and Intermittent Preventive Treatment in pregnancy (IPTp) (Nyan., et al. 2009).

Despite big increases in the supply of mosquito nets, especially of LLINs in Africa, the number available is still far below what is needed in almost all countries (WHO, 2008). Household surveys and data from The Gambia National Malaria Control Programme (NMCP) showed that the coverage of all interventions is lower than the $80 \%$ target set by the World Health Assembly. LLIN usage in the general population is low, given that the average rural household size is approximately 8 only $60 \%$ of rural households have at least one LLIN (Nyan., et al. 2009); less than 50\% of children under 5 years of age sleep under LLINs (Nyan., et al. 2009; GBoS, 2007); 32\% of children with fever were treated with ACT (Nyan., et al. 2009); and 50\% of women used IPT in pregnancy (Nyan., et al. 2009).

The Gambia has made considerable progress in the fight against malaria. The overall malaria parasite prevalence in the country is only 0.2 compared to 4 in 2011 indicating a significant decline of more than 90 in all the health regions of the country. WHO and Roll Back Malaria partners have identified the Gambia as one of seven countries in West African sub-region for accelerated progress towards malaria elimination (NMCP 2017).

The Gambia has a long history of bed net usage. In fact, bed nets usage is seen as part of Gambian tradition, especially in rural areas. Between 2000 and 2009, LLIN distribution targeted the most vulnerable groups; Children under 5 years, pregnant women and the differentially able persons. In 2010, the universal coverage strategy was adopted (MICS 2015).

In 2014, the first nationwide mass LLINs distribution was conducted during which Over 700,000 Nets were distributed. In 2017, the second LLIN distribution campaign was conducted and 911,183 LLINs were delivered.

Household surveys and data from The Gambia National Malaria Control Programme (NMCP) showed that the coverage of all interventions is lower than the $80 \%$ target set by the World Health Assembly. Due to these fact children in the kanifing municipality are 
not benefitting from other interventions such as the seasonal malaria chemotherapy SMC found in other parts of the country. This makes children under five in KM more prone to malaria episodes considering the geographical pattern and socio-demographic factors in the municipality.

Identification of awareness gaps, monitoring of behavioral changes on malaria disease recognition and use of preventive and control measures such as the use of ITNs are a priority area for the Government of The Gambia with a special emphasis on increasing coverage and use of ITNs under national malaria guidelines. Few studies assessed the ownership and use of ITNs by households of under-five children. The research describes magnitude and predictors of ownerships and utilization of ITNs among these vulnerable groups in the selected households in kanifing Municipality.

Objective of the study

The objective of the study is as follows

1. To determine the magnitude of ITNs utilization among households with under-five children in KM.

2. To assess the ownership of ITNs among households of under-five children in KM.

3. To determine the socio-demographic and proximate factors associated with the utilization of ITNs among households with under-five children in KM.

Research questions

The research attempted to answer the following questions

1. What is the ITNs utilization prevalence across the selected sites in KMC?

2. What are the ownership and utilization pattern of ITNs across the selected households of under-five children in KMC?

3. What socio-demographic and proximate factors are associated with ITN utilization among households with under-five children in KM?

Research hypothesis

- $\quad$ Null Hypothesis Ho: There are no statistical differences between utilization and ownership of ITNs with sociodemographic and proximate factors except by chance alone.

- Alternate Hypothesis $\mathbf{H}_{\mathbf{A}}$ : There are statistical differences between utilization and ownership of ITNs with socio-demographic and proximate factors which is not attributed to chance alone.

\section{Material and Methods}

Background information of the study site

The Kanifing Municipality stretches from old Jeswang to Bakoteh and from Bakau to Abuko. It has a total population of 812,395 with an under five populations of 62,658 . The most common occupation among women is business and gardening, and the most common among men are formal employment.

\section{Study design}

A community based cross-sectional study design was employed in this study. Both quantitative and qualitative data was generated and collected using structured questionnaire as it allows meaningful comparison of responses across participants.

\section{Study population}

The study targeted households in the selected EAs (Enumeration Areas) as per Districts within KM, The Gambia.

\section{Inclusion and exclusion criteria}

\section{Inclusion criteria}

Households with at least an under-five child among the selected clusters in a selected EA in KM and of any ethnic group or nationality, present during the time of the study and have consented to participate in the study.

\section{Exclusion criteria}

Those household heads that are unwilling to participate in the study, or do not have any under-five children at the time of the study.

Sample size estimation and sampling technique

By using a fisher's formula for the estimation of a single proportion [2]:

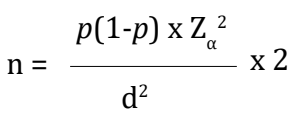

Where

- $\mathrm{Z}^{2}$ the standard normal deviate, which is 1.96 for the $95 \%$ confidence limit

- $\quad \mathrm{p}$ is proportion in the target population estimated to have a particular characteristic. $\mathrm{P}=0.5$ (because of the approximation of households of under-five children properly utilizing ITNs in the area is unknown),

- $\mathrm{d}^{2}$ is a degree of accuracy desired which was set at $5 \%$ (0.05) and

- contingency for non-response rate of $10 \%$, 
Therefore, an estimated minimum sample size of 424 study participants was expected to be enrolled in the study. However as result of limited resources mobilized for the study, a total of 382 participants were recruited for the study.

Sampling selection technique

A multi-stage sampling approach was used to obtain the estimated sample size of 424 households for the study.

- Stage 1: Selection of Districts: At stage one, a total of five districts were randomly selected using the $2016 \mathrm{Mi}-$ crosoft Excel randomization function (a random number which greater 0 and less than 1 . The function returns new a new number each time a spreadsheet recalculates).

- Stage 2: Selection of Enumeration Areas (EAs): For each of the five selected districts at stage one, a total of 4 EAs (taken from $\mathrm{GBoS}$ ) were randomly selected using 2016 Microsoft Excel randomization function in order to have a total of 20 EAs for the study.

- Stage 3: Selection of Households: At the level of each EA, was further demarcated in to three clusters. Out of which, one cluster was randomly selected and all the eligible households was recruited for the study.

- Stage 4: selection of respondent: At the level of selected household, the number of legible respondents was determined by asking for a caregiver of under-five child in the household who were recruited for the study.

Data collection instruments

Structured questionnaire

Data was collected using a pretested structured questionnaire prepared in English and was translated into the three major local languages of KM (Mandinka, Wolof and Fula). The questionnaire included variables related to socio-demographic characteristics, number of household members, net possession, net utilization, and so forth. Pretest was carried out on $5 \%$ of the households that were not literally participants in the actual research work. Necessary modifications were made thereafter. Each filled questionnaire was re-checked just after the administration of the tool to correct wrong responses with a view to assess appropriateness, comprehensiveness of the questions, any ambiguities and inaccuracies. The research work was supervised by one of the Lecturer at the Department of Public and Environmental health.

The public health students in the BSc program at the department of Public and Environmental Health were used to administer the questionnaire through house-to-house visits. Information were primarily collected from the heads of the households (father or mother) or from an adult household member in case this was not possible.

Data processing and analysis

Data was checked for completeness and consistency. The data was entered at once by some trained students research assistants. Coded data was entered, cleaned, and analyzed using SPSS version 20.0 for Windows (SPSS, Chicago, IL, USA). Descriptive summaries (frequencies and proportions) and univariate analysis were computed. Multivariable logistic regression analysis was used to determine ITN ownership and utilization as the main outcome variables.

Adjusted odds ratios (AOR) and their corresponding 95\% confidence intervals (CI) was used to examine the strength of association. The $p$ values of less or equal to 0.05 were considered statistically significant.

\section{Ethical consideration}

Written or verbal consent was obtained from individual respondents of the study. However, the researchers are committed to the development of knowledge in this particular area and are committed to conduct the research with honesty and integrity.

\section{Results and Discussion}

Socio-demographic characteristics of caregivers of children under-five in Kanifing Municipality

Table 1 shows the summary of the socio-demographic characteristics of respondents in Kanifing Municipality. Majority of respondents as caregivers were females $89.0 \%$ whiles male respondents were $11.0 \%$. The mean age of the participants in the study was 39.98 years with standard deviation of \pm 10.91 . When the mean age of male and female caregivers were compared using the independent sample t-test, there was a statistically significant differences at significant level 0.05. Majority of the respondents were between the age group of 35-44 which accounted for 244 (63.9\%) and followed by 25-34 age group for 73 (19.1\%).

In terms of Ethnicity, the larger proportion of the respondents was Mandinkas 128 (33.5\%) while the least were the Manjagos 6 (1.6\%). The numbers of respondents who are working were 185 $(48.4 \%)$ and majority of the caregivers with at least a primary education level accounted for $62.6 \%$ of the overall study subjects. A total of $223(58.4 \%)$ has an estimated monthly income of less than D2000. Business formed the major occupation of these respon- 
Determinants of Ownership and Utilization of Insecticide-Treated Bed Nets for Malaria Control in the Kanifing Municipality, the Gambia

127

dents which accounted for 108 (28.3\%). However, 268 (70.2\%) of the respondents were Married (monogamy), 75 (19.6\%) were never married, whiles 17 (4.5\%) were reported to be in polygamous marriage type.

\begin{tabular}{|c|c|c|}
\hline Variables & Frequency (n) & Percent (\%) \\
\hline \multicolumn{3}{|l|}{ Sex of the respondents } \\
\hline Male & 42 & 11.0 \\
\hline Female & 340 & 89.0 \\
\hline \multicolumn{3}{|l|}{ Age of respondents } \\
\hline $25-34$ & 73 & 19.1 \\
\hline $35-44$ & 244 & 63.9 \\
\hline $45-54$ & 45 & 11.8 \\
\hline 55 and above & 20 & 5.2 \\
\hline \multicolumn{3}{|c|}{ Mean (SD): 33.98( $( \pm 10.91)$} \\
\hline \multicolumn{3}{|c|}{ Family size per household } \\
\hline $1-10$ & 312 & 81.7 \\
\hline $11-20$ & 58 & 15.2 \\
\hline $21-30$ & 12 & 3.1 \\
\hline \multicolumn{3}{|l|}{ Mean (SD): 7.94( \pm 4.93$)$} \\
\hline \multicolumn{3}{|l|}{ Attended school } \\
\hline Yes & 239 & 62.6 \\
\hline No & 143 & 37.4 \\
\hline \multicolumn{3}{|l|}{ Ethnicity } \\
\hline Mandinka & 128 & 33.5 \\
\hline Fula & 75 & 19.6 \\
\hline Wollof & 61 & 16.0 \\
\hline Jola & 53 & 13.9 \\
\hline Serere & 24 & 6.3 \\
\hline Serahuleh & 21 & 5.5 \\
\hline Others & 14 & 3.7 \\
\hline Manjago & 6 & 1.6 \\
\hline \multicolumn{3}{|l|}{ Currently working } \\
\hline Yes & 185 & 48.4 \\
\hline No & 197 & 51.6 \\
\hline \multicolumn{3}{|l|}{ Educational level } \\
\hline Never attended school & 143 & 37.4 \\
\hline Primary & 74 & 19.4 \\
\hline Secondary & 118 & 30.9 \\
\hline
\end{tabular}

\begin{tabular}{|c|c|c|}
\hline Tertiary & 37 & 9.7 \\
\hline Vocational & 10 & 2.6 \\
\hline \multicolumn{3}{|l|}{ Religion } \\
\hline Muslim & 358 & 93.7 \\
\hline Christian & 22 & 5.8 \\
\hline Others & 2 & 0.5 \\
\hline \multicolumn{3}{|l|}{ Occupational status } \\
\hline $\begin{array}{l}\text { Others (Students, not working, } \\
\text { etc.) }\end{array}$ & 133 & 34.8 \\
\hline Business & 108 & 28.3 \\
\hline Household role & 52 & 13.6 \\
\hline Farmer & 39 & 10.2 \\
\hline Civil Servant & 24 & 6.3 \\
\hline Private sector employee & 20 & 5.2 \\
\hline Carpentry/Mechanic/ Welding & 4 & 1.0 \\
\hline Driver & 2 & 0.5 \\
\hline \multicolumn{3}{|l|}{ Average monthly income } \\
\hline Less than D2000 & 223 & 58.4 \\
\hline D2001 - D3000 & 85 & 22.3 \\
\hline D3001 - D4000 & 26 & 6.8 \\
\hline D4001 - D5000 & 26 & 6.8 \\
\hline More than D5000 & 22 & 5.8 \\
\hline \multicolumn{3}{|l|}{ Nationality } \\
\hline Gambian & 328 & 85.9 \\
\hline Guinea Conakry & 25 & 6.5 \\
\hline Senegalese & 20 & 5.2 \\
\hline Nigerian & 4 & 1.0 \\
\hline Sierra Leonean & 2 & 0.5 \\
\hline Other African & 1 & 0.3 \\
\hline Ghanaian & 1 & 0.3 \\
\hline Non African & 1 & 0.3 \\
\hline \multicolumn{3}{|l|}{ Marital status } \\
\hline Married (monogamy) & 268 & 70.2 \\
\hline Never married & 75 & 19.6 \\
\hline Divorced/Separated & 20 & 5.2 \\
\hline Married (polygamy) & 17 & 4.5 \\
\hline Widowed & 2 & 0.5 \\
\hline
\end{tabular}

Table 1: Socio-demographic characteristics of the respondents in Kanifing Municipality, 2018.

Citation: Ousman Bajinka., et al. "Determinants of Ownership and Utilization of Insecticide-Treated Bed Nets for Malaria Control in the Kanifing Municipality, the Gambia". Acta Scientific Microbiology 2.8 (2019): 123-134. 
Magnitude of ITN ownership and preference among caregivers in the Kanifing Municipality

As shown in table 2, $298(78.0 \%)$ possessed bed nets in their households at the time of the study. Furthermore, 321 (84.0\%) of the respondents preferred using the conical/round type of bed nets while as small as 25 (6.5\%) have no specific preference between the available choices. With regards to the net texture, the greater proportion $335(87.7 \%)$ of respondents preferred the soft texture whereas only $26(6.8 \%)$ reported to have no texture preference. Slightly more than half of the respondents 211 (55.2\%) slept under bed net even without having their nets of choice. Almost more than half of the households interviewed, 196 (51.3\%) had $0-2$ bed nets at the time of the study. The mean number of bed nets possessed by each household was 3.30 and standard deviation is \pm 3.58 .

The mean number of sleeping spaces among respondents was 2.51 and standard deviation of \pm 2.81 , with the highest record of 0-2 accounted for 245 (64.1\%) of total respondents. Furthermore, a total of $314(82.2 \%)$ of respondents never used bed nets outside their sleeping spaces. Sources of bed nets acquisition differ from different respondents but majority got theirs from either government health facility 147 (39.7\%) or mass LLIN campaign 179 (48.4\%). Respondents trek $1.65 \mathrm{~km}$ on average to acquire bed nets with a standard deviation of \pm 2.67 . Most respondents travel between $0-2 \mathrm{~km}$ which stands at $315(82.5 \%)$ in order acquire bed nets. From the total number of respondents, only 80 (20.9\%) have reasons for not acquiring bed nets.

\begin{tabular}{|l|c|c|}
\hline Variables & Frequency & Percent \\
\hline Mosquito nets in household & & \\
\hline Yes & 298 & 78.0 \\
\hline No & 84 & 22.0 \\
\hline Net preference by type/shape & 321 & 84.0 \\
\hline Conical/round & 36 & 9.4 \\
\hline Rectangular & 25 & 6.5 \\
\hline Any of the two & & \\
\hline Net preference by texture & 335 & 87.7 \\
\hline Soft & 21 & 5.5 \\
\hline Hard & 26 & 6.8 \\
\hline Any of the two & & \\
\hline Sleeping under net without preference & 171 & 44.8 \\
\hline Yes & 211 & 55.2 \\
\hline No & & \\
\hline Number of bed nets in household & 196 & 51.3 \\
\hline 0 - 2 & & \\
\hline
\end{tabular}

\begin{tabular}{|c|c|c|}
\hline $3-4$ & 95 & 24.9 \\
\hline 5 and above & 91 & 23.8 \\
\hline \multicolumn{3}{|l|}{ Mean (SD): $3.30( \pm 3.58)$} \\
\hline \multicolumn{3}{|l|}{ Number of bed nets in use } \\
\hline $0-2$ & 241 & 63.1 \\
\hline $3-4$ & 88 & 23.0 \\
\hline 5 and above & 53 & 13.9 \\
\hline \multicolumn{3}{|l|}{ Mean (SD): $2.59( \pm 2.94)$} \\
\hline \multicolumn{3}{|c|}{ Number of sleeping places in household } \\
\hline $0-2$ & 128 & 33.5 \\
\hline $3-4$ & 149 & 39.0 \\
\hline 5 and above & 105 & 27.5 \\
\hline \multicolumn{3}{|l|}{ Mean (SD): $3.93( \pm 2.82)$} \\
\hline \multicolumn{3}{|c|}{ Number of nets in sleeping places } \\
\hline $0-2$ & 245 & 64.1 \\
\hline $3-4$ & 87 & 22.8 \\
\hline 5 and above & 50 & 13.1 \\
\hline \multicolumn{3}{|l|}{ Mean (SD): $2.51( \pm 2.81)$} \\
\hline \multicolumn{3}{|l|}{ Using net when sitting outside } \\
\hline Yes & 68 & 17.8 \\
\hline No & 314 & 82.2 \\
\hline \multicolumn{3}{|l|}{ Source of mosquito net* } \\
\hline Mass campaign & 179 & 48.4 \\
\hline Govt. Health Facilities/Posts & 147 & 39.7 \\
\hline Mobile/Outreach clinic & 45 & 12.2 \\
\hline Shops/Market vendors & 28 & 7.6 \\
\hline Friends/Relative/Neighbors & 19 & 5.1 \\
\hline Others & 17 & 4.6 \\
\hline NOG/Private Outreach & 10 & 2.7 \\
\hline NGOs/Private Clinics & 9 & 2.4 \\
\hline Traditional healers & 2 & 0.5 \\
\hline \multicolumn{3}{|c|}{ Distance from health center $(\mathrm{km})$} \\
\hline $0-2.00$ & 315 & 82.5 \\
\hline $2.01-4.00$ & 33 & 8.6 \\
\hline 4.01 and above & 34 & 8.9 \\
\hline \multicolumn{3}{|l|}{ Mean (SD): $1.65( \pm 2.67)$} \\
\hline \multicolumn{3}{|c|}{ Are there factors preventing from acquiring nets } \\
\hline Yes & 80 & 20.9 \\
\hline No & 302 & 79.1 \\
\hline *Multiple responses & & \\
\hline
\end{tabular}

Table 2: Magnitude of ITN ownership and preference among the respondents in Kanifing Municipality, 2018. 
Utilization of ITNs and incidence of malaria among households of under-fives in the Kanifing Municipality

The study revealed that $235(61.5 \%)$ of the respondents used bed nets when sleeping as shown in Table 3. A total of 183 (47.9\%) respondents reported malaria episodes in their households. Half of the respondents did not record any malaria episode in the household, and only 8 (2.1\%) of the respondents had no idea whether a single malaria episode was reported in their household. From a total number of 179 who contracted the disease, 92 (51.4\%) slept under a treated bed nets while 87 (48.6\%) did not sleep under a treated bed net before contracting malaria. Majority of the respondents, 333 (87.2\%) believed that bed nets can help in reducing the incidence of malaria in Kanifing Municipality. Only 18 (4.7\%) of respondents believed that other interventions can reduce the incidence of malaria in the Kanifing Municipality.

\begin{tabular}{|l|c|c|}
\hline Variables & Frequency & Percent \\
\hline Current use of treated bed net & & \\
\hline Yes & 235 & 61.5 \\
\hline No & 147 & 38.5 \\
\hline Malaria episode this season & & \\
\hline Yes & 183 & 47.9 \\
\hline No & 191 & 50.0 \\
\hline Don't know & 8 & 2.1 \\
\hline $\begin{array}{l}\text { Slept under bed net before contracting diseases } \\
\text { (n=179) }\end{array}$ & \\
\hline Yes & 92 & 51.4 \\
\hline No & & 48.6 \\
\hline $\begin{array}{l}\text { Bed net can reduce the incidence of } \\
\text { malaria }\end{array}$ & 333 & 87.2 \\
\hline Yes & 31 & 8.1 \\
\hline No & 18 & 4.7 \\
\hline Other intervention & & \\
\hline *Multiple responses & & \\
\hline
\end{tabular}

Table 3: Utilization of ITN and cases of malaria among the household of under five children in Kanifing Municipality, 2018.

Socio-demographic factors associated with ITN Utilization among the household of under five children in Kanifing Municipality

Table 4 shows the association between socio-demographic factors and utilization of ITNs among the respondents as per household in the study. Majority of the users were found among Mandinkas, Fulas, Jolas, Sarahulehs, Manjagoes, Serere and those in the other categories while Wollofs were found to record the lowest in the utilization of ITNs at the time of the study. The Fisher's exact test results revealed that these difference were statistically significant $(\mathrm{p}=0.022)$.

\begin{tabular}{|c|c|c|c|c|}
\hline \multirow{2}{*}{$\begin{array}{l}\text { Socio-demo- } \\
\text { graphic factors }\end{array}$} & \multicolumn{2}{|c|}{ Current use of ITNs } & \multirow[b]{2}{*}{$\begin{array}{c}\text { Test } \\
\text { Statis- } \\
\text { tics }\end{array}$} & \multirow[b]{2}{*}{$\begin{array}{c}\mathrm{p}- \\
\text { value }\end{array}$} \\
\hline & $\begin{array}{c}\text { Yes } 235 \\
(61.5)\end{array}$ & $\begin{array}{l}\text { No } 147 \\
(38.5)\end{array}$ & & \\
\hline & n (\%) & $\mathrm{n}(\%)$ & & \\
\hline \multicolumn{5}{|c|}{ Sex of the respondents } \\
\hline Male & $24(57.1)$ & $18(42.9)$ & $\chi^{2}$ & 0.537 \\
\hline Female & $211(62.1)$ & $129(37.9)$ & & \\
\hline \multicolumn{5}{|c|}{ Family size per household } \\
\hline $1-10$ & $5(50.0)$ & $5(50.0)$ & $\chi^{2}$ & 0.105 \\
\hline $11-20$ & $36(51.4)$ & $34(48.6)$ & & \\
\hline $21-30$ & $194(64.2)$ & $108(35.8)$ & & \\
\hline \multicolumn{5}{|l|}{ Attended school } \\
\hline Yes & $139(58.2)$ & $100(41.8)$ & $\chi^{2}$ & 0.081 \\
\hline No & $96(67.1)$ & $47(32.9)$ & & \\
\hline \multicolumn{5}{|l|}{ Ethnicity } \\
\hline Mandinka & $86(67.2)$ & $42(32.8)$ & $\dagger$ & $0.022 *$ \\
\hline Wollof & $24(39.3)$ & 37 (60.7) & & \\
\hline Fula & $48(64.0)$ & $27(36.0)$ & & \\
\hline Jola & $35(66.0)$ & $18(34.0)$ & & \\
\hline Serahuleh & $13(61.9)$ & $8(38.1)$ & & \\
\hline Manjago & $5(83.3)$ & $1(16.7)$ & & \\
\hline Serere & $15(62.5)$ & $9(37.5)$ & & \\
\hline Others & $9(64.3)$ & $5(35.7)$ & & \\
\hline \multicolumn{5}{|c|}{ Currently working } \\
\hline Yes & $119(64.3)$ & $66(35.7)$ & $\chi^{2}$ & 0.275 \\
\hline No & $116(58.9)$ & $81(41.1)$ & & \\
\hline \multicolumn{5}{|l|}{ Educational level } \\
\hline $\begin{array}{l}\text { Never attended } \\
\text { school }\end{array}$ & $97(67.8)$ & $46(32.2)$ & $\dagger$ & 0.056 \\
\hline Primary & $47(63.5)$ & $27(36.5)$ & & \\
\hline Secondary & $66(55.9)$ & $52(44.1)$ & & \\
\hline Tertiary & $17(45.9)$ & $20(54.1)$ & & \\
\hline Vocational & $8(80.0)$ & $2(20.0)$ & & \\
\hline \multicolumn{5}{|l|}{ Religion } \\
\hline Muslim & $224(62.6)$ & $134(37.4)$ & $\dagger$ & 0.097 \\
\hline Christian & $11(50.0)$ & $11(50.0)$ & & \\
\hline Others & $0(0.0)$ & $2(100.0)$ & & \\
\hline \multicolumn{5}{|l|}{$\begin{array}{l}\text { Occupational } \\
\text { status }\end{array}$} \\
\hline Farmer & $21(53.8)$ & $18(46.2)$ & $\dagger$ & 0.291 \\
\hline Household role & $35(67.3)$ & 17 (32.7) & & \\
\hline Civil Servant & $11(45.8)$ & $13(54.2)$ & & \\
\hline $\begin{array}{l}\text { Private sector } \\
\text { employee }\end{array}$ & $10(50.0)$ & $10(50.0)$ & & \\
\hline Business & $73(67.6)$ & $35(32.4)$ & & \\
\hline
\end{tabular}




\begin{tabular}{|c|c|c|c|c|}
\hline Driver & $2(100.0)$ & $0(0.0)$ & & \\
\hline $\begin{array}{l}\text { Carpentery/Me- } \\
\text { chanic/ Welding }\end{array}$ & $3(75.0)$ & $1(25.0)$ & & \\
\hline $\begin{array}{l}\text { Others (Stu- } \\
\text { dents, Not } \\
\text { working, etc) }\end{array}$ & $80(60.2)$ & $53(39.8)$ & & \\
\hline \multicolumn{5}{|l|}{$\begin{array}{l}\text { Average month- } \\
\text { ly income }\end{array}$} \\
\hline $\begin{array}{l}\text { Less than } \\
\text { D2000 }\end{array}$ & $143(64.1)$ & $80(35.9)$ & $\chi^{2}$ & 0.739 \\
\hline D2001 - D3000 & $51(60.0)$ & $34(40.0)$ & & \\
\hline D3001 - D4000 & $15(57.7)$ & $11(42.3)$ & & \\
\hline D4001 - D5000 & $14(53.8)$ & $12(46.2)$ & & \\
\hline $\begin{array}{l}\text { More than } \\
\text { D5000 }\end{array}$ & $12(54.5)$ & $10(45.5)$ & & \\
\hline \multicolumn{5}{|l|}{ Nationality } \\
\hline Gambian & $208(63.4)$ & $120(36.6)$ & $\dagger$ & 0.234 \\
\hline Senegalese & $8(40.0)$ & $12(60.0)$ & & \\
\hline Guinea Conakry & $14(56.0)$ & $11(44.0)$ & & \\
\hline Nigerian & $2(50.0)$ & $2(50.0)$ & & \\
\hline Nigerian & $1(100.0)$ & $0(100.0)$ & & \\
\hline Sierra Leonean & $1(50.0)$ & $1(50.0)$ & & \\
\hline Ghanian & $1(100.0)$ & $0(0.0)$ & & \\
\hline Other African & $0(0.0)$ & $1(100.0)$ & & \\
\hline \multicolumn{5}{|l|}{ Marital status } \\
\hline $\begin{array}{l}\text { Married (mo- } \\
\text { nogamy) }\end{array}$ & $166(61.9)$ & $102(38.1)$ & $\dagger$ & 0.200 \\
\hline Never married & $49(65.3)$ & $26(34.7)$ & & \\
\hline $\begin{array}{l}\text { Married (po- } \\
\text { lygamy) }\end{array}$ & $6(35.3)$ & 11 (64.7) & & \\
\hline $\begin{array}{l}\text { Divorced/Sepa- } \\
\text { rated }\end{array}$ & $13(65.0)$ & $7(35.0)$ & & \\
\hline Widowed & $1(50.0)$ & $1(50.0)$ & & \\
\hline \multicolumn{5}{|c|}{$\begin{array}{l}\text { *Statistical significance at } \\
\mathrm{p}<0.05\end{array}$} \\
\hline \multicolumn{5}{|l|}{$\begin{array}{l}\text { †Fisher's exact } \\
\text { test }\end{array}$} \\
\hline $\begin{array}{l}\chi 2 \text { Chi-square } \\
\text { test }\end{array}$ & & & & \\
\hline
\end{tabular}

Table 4: Socio-demographic factors associated with ITN Utilization among the household of under five children in Kanifing Municipality, 2018.
However, other socio-demographic factors were found to be non-statistically significant with the utilization of ITNs and includes the following: sex of the respondent, family size per household, attended school, currently working status, educational level, religion, occupational status, average monthly income, nationality and marital status.

\section{Proximate factors associated with ITN Utilization} among the household of under five children in Kanifing Municipality

As shown in Table 5, the major proximate factors that were found to be statistically significant were as follows: the availability of mosquito nets in the household $\left(\chi^{2}=101.473, \mathrm{df}=1, \mathrm{p}<0.001\right)$, number of bed nets in the household $\left(\chi^{2}=36.242, \mathrm{df}=2, \mathrm{p}<0.001\right)$, number of bed nets in use $\left(\chi^{2}=46.454, \mathrm{df}=2, \mathrm{p}<0.001\right)$, number of bed nets in sleeping places $\left(\chi^{2}=45.510, \mathrm{df}=2, \mathrm{p}<0.001\right)$, use of nets when sitting outside $\left(\chi^{2}=19.754, \mathrm{df}=1, \mathrm{p}<0.001\right)$, opinion on the presence of factors preventing from acquiring nets $\left(\chi^{2}=17.560\right.$, $\mathrm{df}=1, \mathrm{p}<0.001$ ) and sleeping under bed nets before contracting diseases $\left(\chi^{2}=38.991, \mathrm{df}=1, \mathrm{p}<0.001\right)$.

\begin{tabular}{|c|c|c|c|c|}
\hline \multirow{3}{*}{$\begin{array}{l}\text { Proximate } \\
\text { factors }\end{array}$} & \multicolumn{2}{|c|}{ Current use of ITNs } & \multirow{3}{*}{$\begin{array}{c}\text { Test } \\
\text { Statis- } \\
\text { tics }\end{array}$} & \multirow[b]{3}{*}{ p-value } \\
\hline & $\begin{array}{c}\text { Yes } 235 \\
(61.5)\end{array}$ & $\begin{array}{c}\text { No } 147 \\
(38.5)\end{array}$ & & \\
\hline & $\mathrm{n}(\%)$ & n $(\%)$ & & \\
\hline \multicolumn{5}{|l|}{$\begin{array}{l}\text { Mosquito nets } \\
\text { in household }\end{array}$} \\
\hline Yes & $223(74.8)$ & $75(25.2)$ & $\chi^{2}$ & $<0.001 *$ \\
\hline No & $12(14.3)$ & $72(85.7)$ & & \\
\hline \multicolumn{5}{|c|}{ Net preference by type/shape } \\
\hline $\begin{array}{l}\text { Conical/ } \\
\text { round }\end{array}$ & $195(60.7)$ & $\begin{array}{c}126 \\
(39.3)\end{array}$ & $\chi^{2}$ & 0.121 \\
\hline Rectangular & $20(55.6)$ & $16(44.4)$ & & \\
\hline $\begin{array}{l}\text { Any of the } \\
\text { two }\end{array}$ & $20(80.0)$ & $5(20.0)$ & & \\
\hline \multicolumn{5}{|c|}{ Net preference by texture } \\
\hline Soft & $209(62.4)$ & $\begin{array}{c}126 \\
(37.6) \\
\end{array}$ & $\chi^{2}$ & 0.457 \\
\hline Hard & $13(61.9)$ & $8(38.1)$ & & \\
\hline $\begin{array}{l}\text { Any of the } \\
\text { two }\end{array}$ & $13(50.0)$ & $13(50.0)$ & & \\
\hline \multicolumn{5}{|c|}{ Sleeping under net without preference } \\
\hline Yes & $105(61.4)$ & $66(38.6)$ & $\chi^{2}$ & 0.967 \\
\hline
\end{tabular}




\begin{tabular}{|c|c|c|c|c|}
\hline No & $130(61.6)$ & $81(38.4)$ & & \\
\hline \multicolumn{5}{|c|}{ Number of bednet in household } \\
\hline $0-2$ & $92(46.9)$ & $\begin{array}{c}104 \\
(53.1)\end{array}$ & $\chi^{2}$ & $<0.001^{*}$ \\
\hline $3-4$ & $72(75.8)$ & $23(36.6)$ & & \\
\hline 5 and above & $71(78.0)$ & $20(22.0)$ & & \\
\hline \multicolumn{5}{|c|}{ Number of bednet in use } \\
\hline $0-2$ & $117(48.5)$ & $\begin{array}{c}124 \\
(51.5)\end{array}$ & $\chi^{2}$ & $<0.001^{*}$ \\
\hline $3-4$ & $73(83.0)$ & $15(17.0)$ & & \\
\hline 5 and above & $45(84.9)$ & $8(15.1)$ & & \\
\hline \multicolumn{5}{|c|}{ Number of sleeping places in household } \\
\hline $0-2$ & $75(58.6)$ & $53(41.4)$ & $\chi^{2}$ & 0.675 \\
\hline $3-4$ & $95(63.8)$ & $54(36.2)$ & & \\
\hline 5 and above & $65(61.9)$ & $40(38.1)$ & & \\
\hline \multicolumn{5}{|c|}{ Number of nets in sleeping places } \\
\hline $0-2$ & $120(49.0)$ & $\begin{array}{c}125 \\
(51.0)\end{array}$ & $\chi^{2}$ & $<0.001^{*}$ \\
\hline $3-4$ & $72(82.8)$ & $15(17.2)$ & & \\
\hline 5 and above & $43(86.0)$ & 7 14.0) & & \\
\hline \multicolumn{5}{|c|}{ Using net when sitting outside } \\
\hline Yes & $58(85.3)$ & $10(14.7)$ & $\chi^{2}$ & $<0.001^{*}$ \\
\hline No & $177(56.4)$ & $\begin{array}{c}137 \\
(43.6) \\
\end{array}$ & & \\
\hline \multicolumn{5}{|c|}{ Source of mosquito net* } \\
\hline $\begin{array}{l}\text { Govt. Hlth } \\
\text { Facilities/ } \\
\text { Posts }\end{array}$ & $97(66.0)$ & $50(34.0)$ & $\dagger$ & 0.362 \\
\hline $\begin{array}{l}\text { Mobile/Out- } \\
\text { reach clinic }\end{array}$ & $26(57.8)$ & $19(42.2)$ & & \\
\hline $\begin{array}{l}\text { NGOs/Private } \\
\text { Clinics }\end{array}$ & $6(66.7)$ & 3 (33.3) & & \\
\hline $\begin{array}{l}\text { NGO/Private } \\
\text { Outreach }\end{array}$ & $6(60.0)$ & $4(40.0)$ & & \\
\hline $\begin{array}{l}\text { Friends/Rela- } \\
\text { tive/Neigh- } \\
\text { bors }\end{array}$ & $13(68.4)$ & $6(31.6)$ & & \\
\hline $\begin{array}{l}\text { Shops/Mar- } \\
\text { ket vendors }\end{array}$ & $22(78.6)$ & $6(21.4)$ & & \\
\hline $\begin{array}{l}\text { Traditional } \\
\text { healers }\end{array}$ & $1(50.0)$ & $1(50.0)$ & & \\
\hline $\begin{array}{l}\text { Mass cam- } \\
\text { paign }\end{array}$ & $122(68.2)$ & $57(31.8)$ & & \\
\hline Others & $7(41.2)$ & $10(58.8)$ & & \\
\hline
\end{tabular}

\begin{tabular}{|c|c|c|c|c|}
\hline \multicolumn{5}{|c|}{ Distance from health Centre $(\mathrm{km})$} \\
\hline $0-2.00$ & $195(61.9)$ & $\begin{array}{c}120 \\
(38.1)\end{array}$ & $\chi^{2}$ & 0.485 \\
\hline $2.01-4.00$ & $22(66.7)$ & $11(33.3)$ & & \\
\hline $\begin{array}{l}4.01 \text { and } \\
\text { above }\end{array}$ & $18(52.9)$ & $16(47.1)$ & & \\
\hline \multicolumn{5}{|c|}{ Are there factors preventing from acquiring nets } \\
\hline Yes & $33(41.3)$ & $47(58.8)$ & $\chi^{2}$ & $<0.001^{*}$ \\
\hline No & $202(66.9)$ & $\begin{array}{c}100 \\
(33.1)\end{array}$ & & \\
\hline \multicolumn{5}{|c|}{ Malaria episode this season } \\
\hline Yes & $110(60.1)$ & $73(39.9)$ & $\dagger$ & 0.321 \\
\hline No & $118(61.8)$ & $73(38.2)$ & & \\
\hline Don't know & $7(87.5)$ & $1(12.5)$ & & \\
\hline \multicolumn{5}{|c|}{ Outcome of the treatment $(n=183)$} \\
\hline $\begin{array}{l}\text { Treated \& } \\
\text { Discharged }\end{array}$ & $60.7)$ & $64(39.3)$ & $\dagger$ & 0.517 \\
\hline Hospitalized & $11(57.9)$ & $8(42.1)$ & & \\
\hline Died & $0(0.0)$ & $1(100.0)$ & & \\
\hline \multicolumn{5}{|c|}{ Slept under bednet before contracting diseases $(n=179)$} \\
\hline Yes & $75(81.5)$ & $17(18.5)$ & $\chi^{2}$ & $<0.001^{*}$ \\
\hline No & $31(35.6)$ & $56(64.4)$ & & \\
\hline \multicolumn{5}{|c|}{ Bednet can reduce the incidence of malaria } \\
\hline Yes & $212(63.7)$ & $\begin{array}{c}121 \\
(36.3)\end{array}$ & $\chi^{2}$ & 0.054 \\
\hline No & $16(51.6)$ & $15(48.4)$ & & \\
\hline $\begin{array}{l}\text { Other inter- } \\
\text { vention }\end{array}$ & $7(38.9)$ & $11(61.1)$ & & \\
\hline $\begin{array}{l}\text { *Statistical si } \\
\text { †Fisher's exa } \\
\chi 2 \text { Chi-squar }\end{array}$ & $\begin{array}{l}\text { ificance at } p \\
\text { est }\end{array}$ & .05 & & \\
\hline
\end{tabular}

Table 5: Proximate factors associated with ITN Utilization among the household of under five children in Kanifing Municipality, 2018.

On the contrary, some of the proximate factors there were not found to be statistically significant with the utilization of ITNs include the following: Net preference by type/shape $(p=0.121)$, net preference by texture $(\mathrm{p}=0.457)$, sleeping under net without preference $(p=0.967)$, number of sleeping places in the household $(p=0.675)$, source of mosquito nets $(p=0.362)$, distance from health center $(p=0.485)$, episode of malaria in this season $(p=0.321)$, treatment outcome $(p=0.517)$ and reduction of the incidence of malaria by use of bed nets $(\mathrm{p}=0.054)$. 
Final Binary Logistic regression analysis for current utilization of ITNs by socio-demographic and proximate factors among the household of under five children in Kanifing Municipality, 2018

The variables in the model explained $35.0 \%$ to $47.5 \%$ of the variation observed in the current utilization of ITNs among the respondents as shown in Table 6. The model was statistically useful (Omnibus Tests of model coefficient $=164.378 .86, \mathrm{p}<0.001$ ).

With a unit increase in the size of the family in a given household of the respondents were 0.855 (95\% CI: 0.798 - 0.916) times less likely to utilized ITNs among the respondents.

The respondents who were having mosquito nets in their households were 11.806 (95\% CI: 5.513 - 25.279) times more likely to utilized ITNs compared to those who were not having mosquito nets in their households. The households who were having nets in their sleeping spaces were 1.732 (95\% CI: 1.443 - 2.078) times as likely to utilized ITNs compared to those who were not having nets in their sleeping spaces across the respondents in the study.

The study respondents who reported that bed net can reduce the incidence of malaria were 3.902 (95\% CI: 1.215 - 12.531) times more likely to utilized ITNs compared to those who reported other interventions beside bed net as a mean of reducing the incidence of malaria.

In this study we examined the determinants of ownership and utilization of treated bed nets among households in the kanifing municipality. Socio-demographic and proximate factors were used to established the relationship between ownership and utilization of treated bed nets.

\begin{tabular}{|c|c|c|c|c|c|c|}
\hline & $\begin{array}{c}\text { B (Regression } \\
\text { coefficient) }\end{array}$ & P-value & COR (95\% C.I.) & $\begin{array}{c}\text { B (Regression } \\
\text { coefficient) }\end{array}$ & P-value & AOR (95\% C.I.) \\
\hline $\begin{array}{l}\text { Size of the family in a } \\
\text { household }\end{array}$ & 0.016 & 0.466 & $1.016(0.973-1.061)$ & -0.157 & 0.000 & $0.855(0.798-0.916)$ \\
\hline \multicolumn{7}{|c|}{$\begin{array}{l}\text { Mosquito nets in house- } \\
\text { hold }\end{array}$} \\
\hline Yes & 2.881 & 0.000 & $17.840(9.177-34.682)$ & 2.469 & 0.000 & $11.806(5.513-25.279)$ \\
\hline $\mathrm{No}^{*}$ & & & 1 & & & 1 \\
\hline \multicolumn{7}{|l|}{ Nets in sleeping spaces } \\
\hline Yes & 0.644 & 0.000 & $1.905(1.600-2.267)$ & 0.549 & 0.000 & $1.732(1.443-2.078)$ \\
\hline $\mathrm{No}^{*}$ & & & 1 & & & 1 \\
\hline \multicolumn{2}{|c|}{ Bed net can reduce the incidence of malaria } & 0.012 & & & 0.012 & \\
\hline Yes & 1.013 & 0.041 & $2.753(1.040-7.289)$ & 1.361 & 0.022 & $3.902(1.215-12.531)$ \\
\hline No & 0.517 & 0.391 & $1.676(0.515-5.459)$ & 0.426 & 0.550 & $1.531(0.378-6.203)$ \\
\hline Other interventions* & & & 1 & & & 1 \\
\hline Constant & -2.655 & 0.000 & & -2.655 & 0.000 & \\
\hline \multicolumn{7}{|c|}{$\begin{array}{l}\text { R2 }=35.0 \%-47.5 \%, \text { Omnibus Tests of model coefficient }=164.378 \text { ( } \mathrm{p} \text { value }=0.000), \text { * Reference category, COR=Crude Odds Ratio, } \\
\text { AOR=Adjusted Odds Ratio, CI=Confidence Interval } \\
\text { (Dependent variable was current utilization of ITNs) }\end{array}$} \\
\hline
\end{tabular}

Table 6: Final Binary Logistic regression analysis for current utilization of ITNs by socio-demographic and proximate factors among the household of under five children in Kanifing Municipality, 2018. 
Socio-demographic factor that was statistically significant was found to be ethnicity. Ethnicity is link to culture. Since the Wolof were the ethnicities with the lowest utilization rate in the study. The researcher can link cultures such as; regarding malaria as caused by other spiritual factors as well as other myths may hinder people from using bed nets. Education level, family size, marriage status, economic status was not found to be statistically associated with bed nets utilization. The finding was in agreement with those from a study in Port Harcourt Nigeria by (C. I Tobin-West., et al. 2016). On the contrary studies done in Eastern Ethiopia states that education level has a significant association with bed nets utilization.

The study further reveals that $78.0 \%$ of respondents have bed nets in their households. These ITNs include those in use and those in the cupboards, further more in establishing whether all the bed nets available were in used, the study reveal the number of use of bed nets in each household. From the class intervals listed, majority of households used between $0-2$ bed nets amounting to $63.1 \%$ from the total study site. The proximate factors that were significantly associated with bed nets utilization in the study were; number of bed nets in the household, number of bed nets in use, number of nets in sleeping spaces, using nets when sitting outside, and factors preventing from acquiring bed nets. A similar study in Mozambique by (M.M. Plucinski., et al. 2015) indicates that using sleeping spaces during distribution can affect utilization of bed nets within a household. On the contrary, factors such as net preference by texture or shape as well as sleeping under bed net without preference, number of sleeping places in household has no significant statistical association with bed nets utilization.

The study reveals that majority of individuals in the Kanifing municipality utilized bed nets in their sleeping spaces. A total utilization rate of $61.5 \%$ was reported during the study, which is below the World Health Assembly set target for malaria intervention. A margin of ownership and utilization was discovered during the study which commensurate with a study conducted in Ethiopia by (Amsalu., et al. 2009). As nationwide distributions routinely take place but still utilization is low. The last nationwide distribution in the Gambia amounted to 911,183 bed nets. Despite the high coverage of distribution in recent years, ownership remain less than utilization. A similar study was carried out in Uganda by (R. Sangare., et al. 2012).
Although ownership was seemingly high but utilization was below ownership with a significant difference which was also revealed in a similar study conducted in Southwest Nigeria. Though ownership was high but $61.5 \%$ slept under a bed net a night preceding the study. Majority of respondents' belief that the bed net utilization as a malaria intervention is able to reduce the incidence, and prevalence in the kanifing Municipality.

Furthermore the study revealed that $82.2 \%$ don't use bed nets outsides their sleeping spaces despite having the bed nets in their sleeping spaces. This reveals that inhabitants have contact with mosquitoes outside their sleeping spaces especially during hot weather conditions. This makes most households suffer one or more malaria episode in the season. A total of $47.9 \%$ had at least a single episode of malaria within each household. However, 51.4\% didn't sleep under a bed net before contracting the disease. The other percentage slept under bed nets and still contracted malaria. The researcher realized that many inhabitants usually stay late outside due to extreme weather condition and power failures [316].

\section{Conclusion}

Despite free distribution of LLINs during mass campaigns and routine government health facilities distribution, the ownership was moderately high and utilization remains low. Thus, there is a need to refocus on people's choice of bed nets including the textural properties in order to increase the utilization of ITN to effectively and efficiently control malaria in the municipality. Furthermore, the distribution centers and bed nets choices of individuals as in conical and soft texture should be increased during routine and mass LLIN campaigns.

\section{Recommendations}

1. Increase the number of conical despite the cost attached

2. Train individuals in the procedures involved in redesigning the rectangular bed nets to conical

3. Increases awareness on utilization through mass advocacy using both print and electronic media

4. Increase the number of bed nets and centers of distributions during mass LLINs campaign.

\section{Acknowledgements}

The researchers wish to acknowledge Mr. Amadou Barrow for supervising the whole research. Words cannot express how inspi- 
red we are to work with you but a thank you for now will do. A special thanks goes to Mr. Alieu Bah "Senior Man" at CRS for printing the Questionnaires and for inspiring us to engage in this research. Again thumbs up to my mentor Mr. Lamin BS Jarju, Entomologist and Deputy Program Manager National Malaria Control Program for the guidance and support during the course of the research.

A final thank you to the Executive of SAPEH and the general student body for the volunteering during the data collection exercise and the entering of the Data into the SPSS software.

\section{Conflict of Interest}

No conflict of interest exists.

\section{Bibliography}

1. WHO. World malaria report. Geneva, Switzerland: World Health Organization (2015).

2. Wane W. Estimation. Biostatistics: a foundation for analysis in the health sciences. 8th ed. (2005).

3. Greenwood B., et al. "Mortality and morbidity from malaria among children in a rural area of The Gambia, West Africa". Transactions of The Royal Society of Tropical Medicine and Hygiene 81 (1987): 478-86.

4. Isah A and Nwobodo E. "Awareness and utilization of insecticide treated mosquito nets among pregnant mothers at a tertiary health institution in North-Western Nigeria". Nigerian Journal of Medicine 18 (2009): 175-178.

5. WHO. World malaria report. Geneva, Switzerland: World Health Organization (2011).

6. Barrier analysis study conducted by CRS in 2010 .

7. Roll back malaria and WHO 2000.

8. Gambia Bureau of Statistic. The Gambia, Kanifing Institutional Layout (2007).

9. Eisele T.P., K.A. Lindblade, K.A. Wannemuehler, J.E. Gimnig, F. Odhiambo, W.A. Hawley, F.O. ter Kuile, P. Phillips-Howard, D.H. Rosen, B.L. Nahlen, J.M. Vulule, and L. Slutsker. 2005.

10. Sibhatu Biadgilign., et al. "Determinants of ownership and Utilization of Insecticide-Treated Bed Nets for malaria control in Eastern Ethiopia". Journal of Tropical Medicine (2012).
11. Ayalew Astatkie and Amsalu Feleke. "Utilization of insecticide treated bed nets in Arbaminch Town and Malarious villages of Arbaminch Zuria District, Southern Ethiopia". Ethiopian Journal of Health Development (2009).

12. Laura R Sangare., et al. "Determinants of Use of Insecticide Treated Bednets for the prevention of malaria in pregnancy: Jinja, Uganda". (2012).

13. EO Ugwu., et al. "Utilization of treated bed nets among pregnant women in Enugu, South Eastern Nigeria". Nigerian Journal of Clinical Practice (2013).

14. AH Watiro and W Awoke. "Insecticide treated net ownership and utilization and factors that influence their usage in Itang, Gambella Region, Ethiopia”. Pan African medical journal (2016).

15. Charles Ibiene Tobin-West and Esther Njideka Kanu. "Factors influencing the use of malaria preventive methods among women of reproductive age in peri-urban communities in Port Harcourt City, Nigeria". Nigerian Post Graduate Medical Journal (2016).

16. MM Plucinski., et al. "Sleeping arrangement and mass distribution of bed nets in six districts in central and northern Mozambique". Tropical Medicine and International Health Journal 20 (): 1685-1695.

\section{Volume 2 Issue 8 August 2019 (C) All rights are reserved by Ousman Bajinka., et al.}

